\title{
Using Locally Generated Magnetic Indices to Characterize the Ionosphere From Magnetic Data Acquisition System (Magdas) Ground Based Observatories in Nigeria.
}

By

Achem $^{1}$, U.C., Rabiu ${ }^{2}$, A.B., Onimisi ${ }^{3}$, M.Y.

\begin{abstract}
This work presents an attempt to establish a baseline for geomagnetic indices in Nigeria. This is particularly very crucial since these indices give indications of the severity of magnetic fluctuations, and hence the level of disturbances in the ionosphere. $\mathrm{K}$ (an index which measures the magnetic perturbations of the planetary field) and A (a linear measure of the Earth's field that provides a daily average level for geomagnetic activity) geomagnetic indices were generated locally from geomagnetic data obtained using ground based MAGDAS magnetometers located at Abuja $\left(9^{\circ} 40^{\prime} \mathrm{N}, 7^{\circ} 29^{\prime} \mathrm{E}\right)$, Ilorin $\left(8^{\circ} 30^{\prime} \mathrm{N}, 4^{\circ} 33^{\prime} \mathrm{E}\right)$ and Lagos $\left(6^{\circ} 27^{\prime} \mathrm{N}\right.$, $3^{\circ} 23^{\prime} \mathrm{E}$ ) in Nigeria using Computer-based derivation. The indices generated were used to characterize the ionosphere over the Magdas magnetometer Nigeria network stations. Results obtained showed average $K$ values of 3.5 (ABU), 4.60 (LAG) and 4.13 (ILR), the ionosphere over the three stations was found to be relatively active (4.08) thus setting the baseline for characterizing the ionosphere over Nigeria from ground based magnetometers.
\end{abstract}

Key words: Magnetic Indices, Ionosphere, Magnetic Data Acquisition System, Magnetic Fluctuations and Critical Infrastructures.

\section{Introduction}

Free electrons do not appear over the whole of the atmosphere. Instead it is found that the number of free electrons starts to rise at altitudes of approximately $30 \mathrm{~km}$. However it is not until altitudes of around 60 to $90 \mathrm{~km}$ are

1. Centre for Satellite Technology Development, Abuja, Nigeria.

2. National Space Research and Development Agency, Abuja, Nigeria.

3. Nigerian Defence Academy, Kaduna, Nigeria. 
reached that the concentration is sufficiently high to start to have a noticeable effect on radio signals and hence on radio communications systems, it is at this level that the ionosphere can be said to start (1). The ionosphere can thus be defined as the upper part of the atmosphere where electrons and charged particles exist in sufficient proportion as to affect the propagation of radio waves. Thus the ionosphere is a conducting medium in the upper atmosphere. According to (2) the idea of this upper atmospheric conducting medium was used by Lord Kelvin, in 1800, to explain atmospheric electricity.

The ionosphere which forms the inner edge of the magnetosphere affects a wide array of various missions. The future success of geo-location (the act of locating and/or tracking an enemy using high frequency signals) as well as satellite missions, remains highly dependent on our ability to accurately measure and predict the dynamic state of the ionosphere (3), The ionosphere is a particularly important region with regards to radio signal propagation and radio communications in general. It influences radio propagation to distant places on the Earth (4) and its properties govern the ways in which radio communications, particularly in the high frequency (HF) radio communications bands take place (1).

The exigency for services that provide real-time assessment of the (global and local) geomagnetic activity are identified as being of importance to space weather research and modeling, exploration geophysics, radio communications, satellitebased positioning/navigation (5) led to the first attempt to characterize geomagnetic activity as early as 1885 . It was aimed at estimating geomagnetic disturbances on a daily basis. The degree of magnetic disturbance during each Greenwich day is indicated by a variety of indices adopted internationally (6). According to (7), (8) and (9) geomagnetic indices are simple measures of magnetic activity that occurs, typically, over periods of time of less than a few hours and is recorded by magnetometers at ground-based observatories which provide an estimate for the level of activity in the interaction between the Earth's magnetic field and the solar wind. The variations that these indices measures have their origin in the Earth's ionosphere and magnetosphere, According to (10), by comparing indices values, the relative activity level of the Magnetosphere and Ionosphere system is determined.

Some indices are designed specifically to quantify idealized physical processes, while others function as more generic measures of magnetic activity (5). To indicate the state of geomagnetic activity, there are two indices used that are related to each other: $\mathbf{K}$ and $\mathbf{A}$ Index. Although different, these indices give indications of the severity of magnetic fluctuations, and hence the level of disturbances in the ionosphere. It is useful to point out that all data used in the computation of the indices are recorded on three component magnetometers. 
Bartels developed the $\mathrm{K}$ index (11); this index measures the magnetic perturbations of the planetary field. It is the most widely used. The $\mathrm{K}$ index is a quasi-logarithmic index characterizing the 3-hourly range intransient magnetic activity relative to the regular "quiet-day" activity for a single site location. K derived planetary indices, such as $\mathrm{Kp}$ derived from $\mathrm{K}$ indices; provide convenient measures of the global geomagnetic activity (5). The amplitude range $\mathrm{R}$ is used to define a particular $\mathrm{K}(12)$. The values of the $\mathrm{K}$ index range from 0 (indicating "quiet" conditions) to 9 (indicating "severe storm" conditions). The index, valid over a shorter time interval than a day, showed diurnal, seasonal and latitude variations (13). The $\mathrm{K}$ scale for a standard middle latitude station is the Niemegk: $52^{\circ} 04^{\prime} \mathrm{N}, 12^{\circ} 40^{\prime} \mathrm{E}$. Each observatory has a scale like the one shown for the Niemegk Observatory (14).

The A index is a linear measure of the Earth's field, it is based on a linear scale rather than on a quasi-logarithmic scale. As a result of this, its values extend over a much wider range. It is derived from the $\mathrm{K}$ index by scaling it to give a linear value which is termed the "a" index. This is then averaged over the period of a day to give the A index. Values for the A index range up to 100 during a storm and may rise as far as 400 in a severe geomagnetic storm (15). Likewise the daily equivalent planetary amplitude 'Ap', which is the average of the eight ap values computed for each 3-hour interval. The 3-hour index ap is obtained directly from $\mathrm{Kp}$ and hence is based only on mid latitude observations.

The primary objective of this present work is to exploit for the first time locally obtained geomagnetic data from ground based MAGDAS magnetometers, installed in Africa, to characterize the ionosphere over the Magdas magnetometer Nigeria network stations by engaging locally generated magnetic $\mathrm{K}$ and $\mathrm{A}$ indices.

\section{Data}

The data for the study consists of seconds values of the horizontal $(\mathrm{H})$ component of the geomagnetic field obtained from Magnetic Data Acquisition System (MAGDAS) ground based observatories at three (3) Nigerian stations; viz: Abuja, Ilorin and Lagos. The co-ordinates of these stations are given in Table 1. List of International quiet days and daily mean global Ap and Kp indices were also obtained from the UK Solar System Data Centre.

MAGDAS, an acronym of the Magnetic Data Acquisition System, is a project of the Space Environment Research Centre of the Kyushu University, Japan, that has distributed about 15 Magnetometers over Africa up to date. Details of MAGDAS, its deployment, instrumentation, and research capability are documented in (16), (17), (18), (19), (20) and (21). 
Table 1: Location and Co-ordinates of MAGDAS ground based observatories in Nigeria.

\begin{tabular}{|c|c|c|c|c|c|c|}
\hline $\begin{array}{l}\text { Station } \\
\text { Name }\end{array}$ & $\begin{array}{l}\text { Geographic } \\
\text { Latitude }\end{array}$ & $\begin{array}{l}\text { Geographic } \\
\text { Longitude }\end{array}$ & $\begin{array}{l}\text { Geomagnetic } \\
\text { Latitude }\end{array}$ & $\begin{array}{l}\text { Geomagnetic } \\
\text { Longitude }\end{array}$ & $\mathrm{L}$ & $\begin{array}{l}\text { Dip } \\
\text { Lat. }\end{array}$ \\
\hline Abuja & $8.99^{0}$ & $7.39^{0}$ & $-0.54^{0}$ & $81.31^{0}$ & $1.00^{\circ}$ & $-0.95^{0}$ \\
\hline Ilorin & $8.50^{\circ}$ & $4.68^{0}$ & $-1.82^{0}$ & $76.80^{\circ}$ & $1.00^{\circ}$ & $-2.96^{0}$ \\
\hline Lagos & $6.48^{0}$ & $3.27^{0}$ & $-3.04^{0}$ & $75.33^{0}$ & $1.00^{\circ}$ & $-4.95^{0}$ \\
\hline
\end{tabular}

A MAGDAS unit consists of magnetometer/sensor and data acquisition unit which is supplemented by a solar power system unit comprising of a solar panel, inverter and battery, as well as a wireless internet link. The science of MAGDAS and its application to study space weather and environment has been discussed in Yumoto and MAGDAS Group (16). MAGDAS has grown to become a strong component of the International Heliophysical Year IHY (21). This is an extensive international programme to study the universal physical processes in the heliospace for a better understanding of the sun heliosphere system. (18).

\section{Methodology}

A digital magnetometer record of the $\mathrm{H}$ component for eight 3-hourly Universal Time (UT) intervals was first obtained, The $\mathrm{H}$ component data was then converted from the MGD file format to text format using Matlab ${ }^{\circledR}$ code, the data obtained was inspected, screened and cleaned to check for noise, data gaps and spurious non-physical data values (outliers/spikes) which are common problems associated with data acquisition from digital magnetometers. The text file format was thus used in a user program code written in JAVA to estimate the daily real time " $\mathrm{K}$ " index values as follows;

The $\mathrm{H}$ seconds data were first converted to $24 \mathrm{H}$ hourly values $\{\mathrm{H} 1 \ldots \mathrm{H} 24\}$.

The five (5) quietest days for each month was entered (q1, q2, q3, q4, q5) into the program code in order to estimate the mean solar quiet daily variation i.e. The hourly means of $\mathrm{H}$ on the five international quiet days were estimated for every month and obtained as $\{\mathrm{Q} 1 \ldots . . . \mathrm{Q} 24\}$.

The hourly solar regular variation in $\mathrm{H}$ for every day in a particular month is estimated by subtracting corresponding monthly hourly solar regular (SR) mean values of $\mathrm{H}$ on quiet days $\{\mathrm{Q} 1 \ldots \ldots \ldots . . \mathrm{Q} 24\}$ from the hourly values of $\mathrm{H}$ such that on a particular day $(\mathrm{t})$;

$\mathrm{SR}(\mathrm{t})=\mathrm{H}(\mathrm{t})-\mathrm{Q}(\mathrm{t})$. 
The program code also repeats the above process for all the days of the available data. The result of the solar regular (SR) is therefore used to calculate the Range The Range is the difference between the solar regular (SR) variation maximum and minimum values within the pre-defined 3-hour time interval i.e. Range $=$ (Highest - Lowest) Value within 3 hour Interval.

Finally, the 8 Range Values is then converted to $\mathrm{K}$ Index using the $\mathrm{K}$ index class limit table for the standard observatory and $\mathrm{K}$ index value is also used to derive the corresponding A values.

The daily and monthly absolute mean of the $8 \mathrm{~K}$ and $\mathrm{A}$ values is calculated alongside the Yearly $\mathrm{K}$ and $\mathrm{A}$ index for the stations and thus weighted to give the locally generated planetary Kp and Ap Index.

The following analyses were performed in order to establish a better relationship between variables using the Matlab ${ }^{\circledR}$ software;

a. The correlation coefficient ' $r$ ' which is one of the most widely used statistics measures the degree of association between two values of related variables given in a data set. It takes values from +1 to -1 . If two sets or data have $r=+1$, they are said to be perfectly correlated positively; if $r=-1$ they are said to be perfectly correlated negatively; and if $r=0$ they are uncorrelated. $r>0$ implies a direct linear relationship, $\mathrm{r}<0$ implies an inverse linear relationship and the closer $\mathrm{r}$ comes to either +1 or -1 , the stronger the linear relationship. The coefficient of correlation ' $\mathrm{r}$ ' between two variables ( $\mathrm{x}$ and $\mathrm{y}$ ) is given by the formula

$$
r=\left[n \sum x y-\left(\sum x\right)\left(\sum y\right)\right] \div\left[\sqrt{\left\{n\left(\sum x^{2}\right)-\left(\sum x\right)^{2}\right\}\left\{n\left(\sum y^{2}\right)-\left(\sum y\right)^{2}\right\}}\right]
$$

b. The coefficient of determination $\left(\mathrm{r}^{2}\right)$ which is another important measure of linear association between $\mathrm{x}$ and $\mathrm{y}\left(\begin{array}{lll}0 & \mathrm{r}^{2} & 1\end{array}\right)$, it measures the proportion of the total variation in $\mathrm{y}$ which is explained by $\mathrm{x}$, it is statistically defined as; $\mathrm{r}^{2}(\%)=($ correlation coefficient $) *($ correlation coefficient $)$.

c. Two way sample $\mathrm{t}$-test $[\mathrm{h}, \mathrm{p}]=\operatorname{ttest} 2(\mathrm{x}, \mathrm{y})]$ which performs a $t$-test of a null hypothesis that data in the vectors $\mathrm{x}$ and $\mathrm{y}$ are independent random samples from normal distributions with equal means and equal but unknown variances, against the alternative that the means are not equal between variables. The result of the test is returned in $\mathrm{h} . \mathrm{h}=1$ indicates a rejection of the null hypothesis at the $5 \%$ significance level while $\mathrm{h}=0$ indicates a failure to reject the null hypothesis at the $5 \%$ significance level. It also returns the p-value of the test. The p-value is the probability, under the null hypothesis, of observing a value as extreme or more extreme of the test statistic

$t=\{\bar{x}-\bar{y}\} \div \sqrt{\left(s_{x} \wedge 2 / n+s_{y} \wedge 2 / n\right)}$ 
Where $\bar{x}$ and $\bar{y}$ are the sample means, $\mathrm{s}_{\mathrm{x}}$ and $\mathrm{s}_{\mathrm{y}}$ are the sample standard deviations and $\mathrm{n}$ and $\mathrm{m}$ are the sample sizes.

\subsection{Algorithm and Codes}

A Schematic diagram of the algorithm that was used in determining the "daily real time $\mathrm{K}$ index value" is shown below. A program code written in MATrix LABoratory (Matlab®) Software was used to convert the $\mathrm{H}$ component data from 'MGD' file format to 'TXT' file format. The TXT file format is thus used in a user program code in JAVA to estimate the daily real time " $\mathrm{K}$ " index value.


Figure 1: Schematic diagram of an algorithm used in determining the "daily real time $K$ index value". 


\section{RESULTS AND DISSCUSSION}

Table 2: Sample results of locally generated $\mathrm{K}$ and A Magnetic Indices for the month of November at ABU Station

\begin{tabular}{|c|c|c|c|c|c|c|c|}
\hline YEAR & MONTH & DAY & K & A & DAY & K & $\bar{A}$ \\
\hline \multirow[t]{12}{*}{2010} & $\mathrm{NOV}$ & 8 & 9 & 400 & 20 & 2 & 7 \\
\hline & & 9 & 2 & 7 & 21 & 9 & 400 \\
\hline & & 10 & 2 & 7 & 22 & 2 & 7 \\
\hline & & 11 & 3 & 15 & 23 & 2 & 7 \\
\hline & & 12 & 9 & 400 & 24 & 9 & 400 \\
\hline & & 13 & 2 & 7 & 25 & 9 & 400 \\
\hline & & 14 & 2 & 7 & 26 & 2 & 7 \\
\hline & & 15 & 0 & 0 & 27 & 2 & 7 \\
\hline & & 16 & 9 & 400 & 28 & 2 & 7 \\
\hline & & 17 & 9 & 400 & 29 & 2 & 7 \\
\hline & & 18 & 9 & 400 & 30 & 9 & 400 \\
\hline & & 19 & 1 & 4 & & & \\
\hline
\end{tabular}


Table 3: Results of correlation coefficient ' $r$ ', coefficient of determination $\left(r^{2}\right)$ and Two way sample t-test $[\mathrm{h}, \mathrm{p}]=$ ttest $2(\mathrm{x}, \mathrm{y})]$ for ABU Station result

\begin{tabular}{|l|l|l|l|l|l|}
\hline \multicolumn{2}{|l|}{ Corrcoeff (R) } & $\mathrm{R}^{2}$ & Ttest2: & \multicolumn{2}{l|}{$\mathrm{P}$} \\
\hline K and A & 0.9882 & $97.65 \%$ & K and Kp & 1 & 0.0015 \\
\hline Kp and Ap & 0.9495 & $90.16 \%$ & A and Ap & 1 & $3.3562 \mathrm{e}-006$ \\
\hline & & & K and Ap & 1 & $3.8581 \mathrm{e}-059$ \\
\hline & & & A and Kp & 1 & 0 \\
\hline
\end{tabular}

Table 4: Results of correlation coefficient ' $r$ ', coefficient of determination $\left(r^{2}\right)$ and Two way sample t-test $[\mathrm{h}, \mathrm{p}]=$ ttest $2(\mathrm{x}, \mathrm{y})]$ for ILR Station

\begin{tabular}{|c|c|c|c|c|c|}
\hline \multicolumn{2}{|l|}{ Corrcoeff } & \multirow{2}{*}{$\begin{array}{l}\mathrm{R}^{2} \\
97.56 \%\end{array}$} & \multicolumn{2}{|c|}{ Ttest2: } & $\mathrm{p}$ \\
\hline $\mathrm{K}$ and $\mathrm{A}$ & 0.9877 & & $\mathrm{~K}$ and $\mathrm{Kp}$ & 1 & 7.7716e-016 \\
\hline \multirow[t]{3}{*}{ Kp and Ap } & 0.9121 & $83.19 \%$ & $A$ and $A p$ & 1 & 0 \\
\hline & & & $\mathrm{K}$ and $\mathrm{Ap}$ & 1 & 0 \\
\hline & & & $\mathrm{A}$ and $\mathrm{Kp}$ & 1 & 0 \\
\hline & & & & & \\
\hline
\end{tabular}


Table 5: Results of correlation coefficient ' $r$ ', coefficient of determination $\left(\mathrm{r}^{2}\right)$ and Two way sample t-test $[\mathrm{h}, \mathrm{p}]=$ ttest $2(\mathrm{x}, \mathrm{y})]$ for LAG Station.

\begin{tabular}{|l|l|l|l|l|l|}
\hline Corrcoeff & \multicolumn{2}{l|}{ Rtest2: h } \\
\hline K and A & 0.9920 & $98.41 \%$ & K and Kp & 1 & 0.0018 \\
& & & & & \\
\hline Kp and Ap & 0.9510 & $90.44 \%$ & A and Ap & 1 & 0 \\
\hline & & & K and Ap & 1 & 0 \\
\hline & & & & & \\
\hline & & & & & \\
\hline
\end{tabular}




\subsection{Plots}

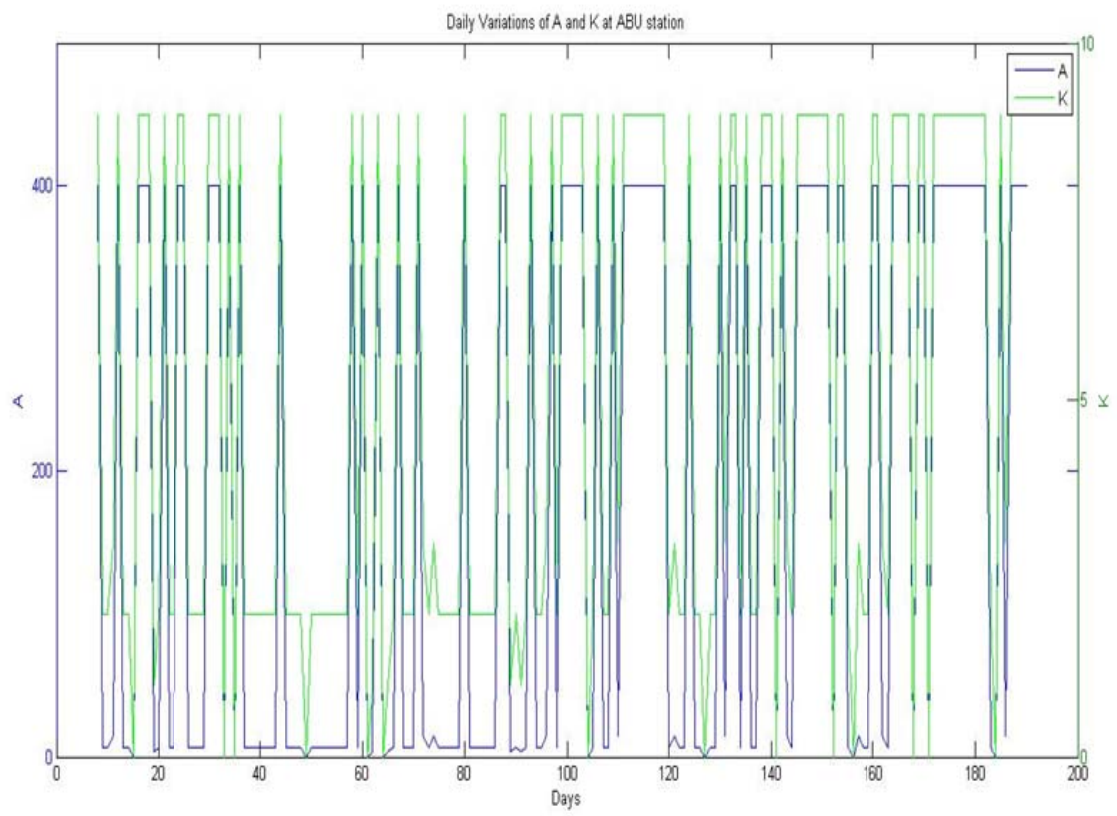

Figure 2: Daily variations of $A$ and $K$ at $A B U$ Stations.

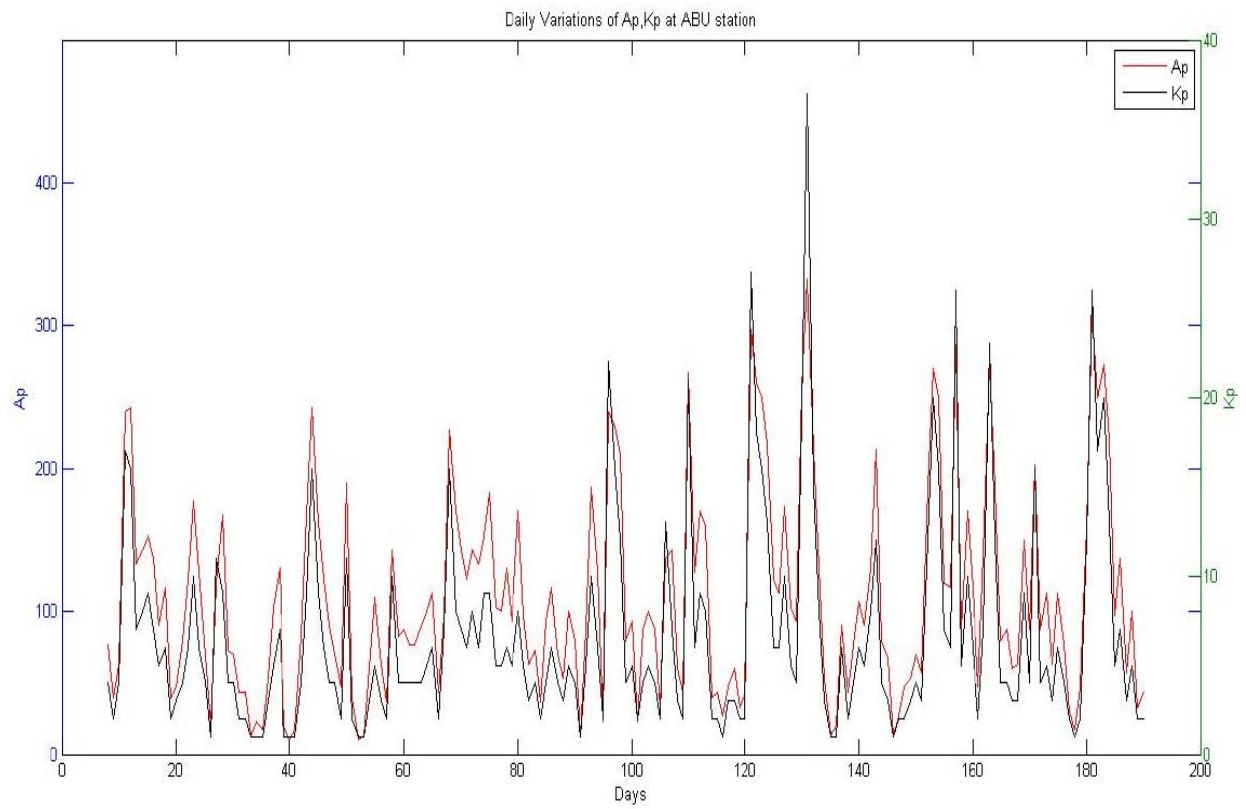

Figure 3: Daily variations of $A p$ and $K p$ at $A B U$ Stations. 


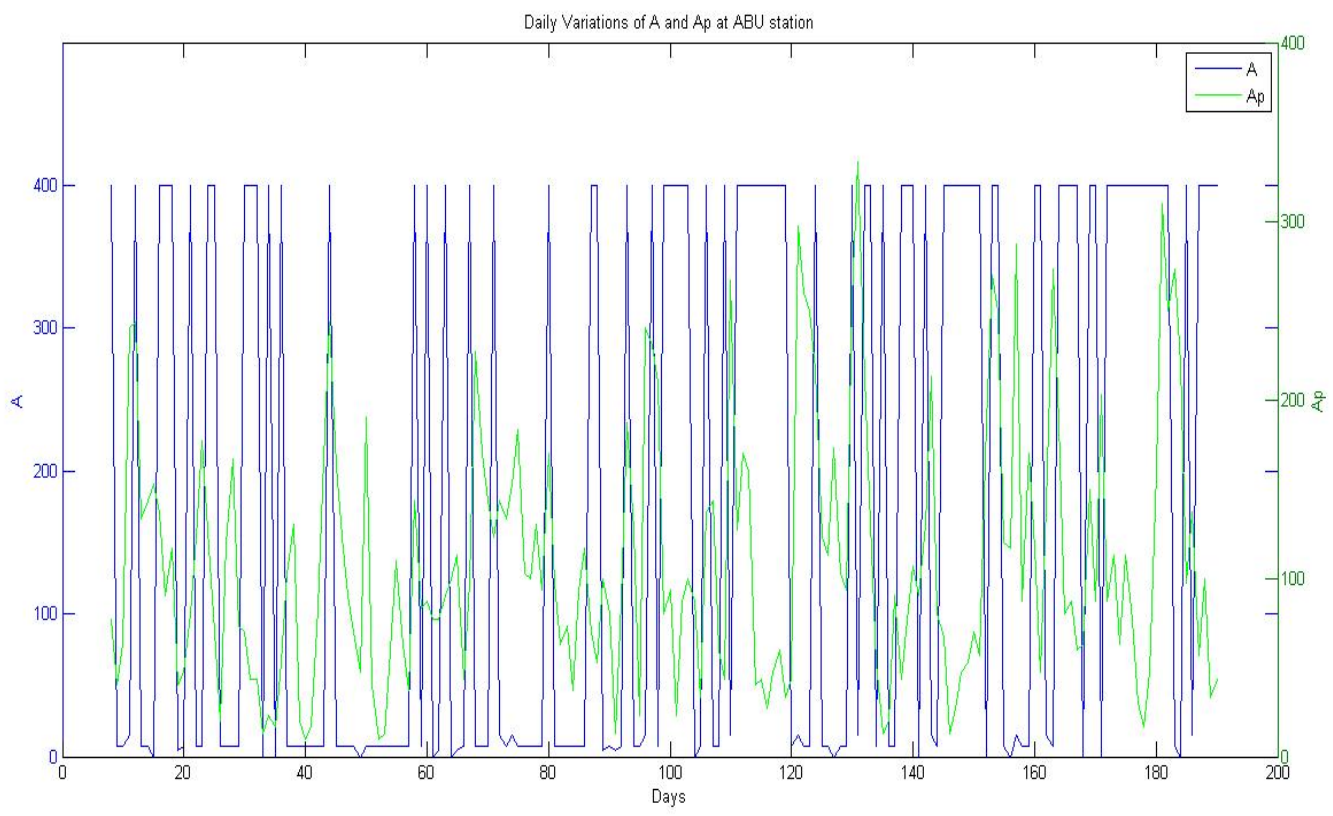

Figure 4: Daily variations of $A$ and $A p$ at $A B U$ Stations.

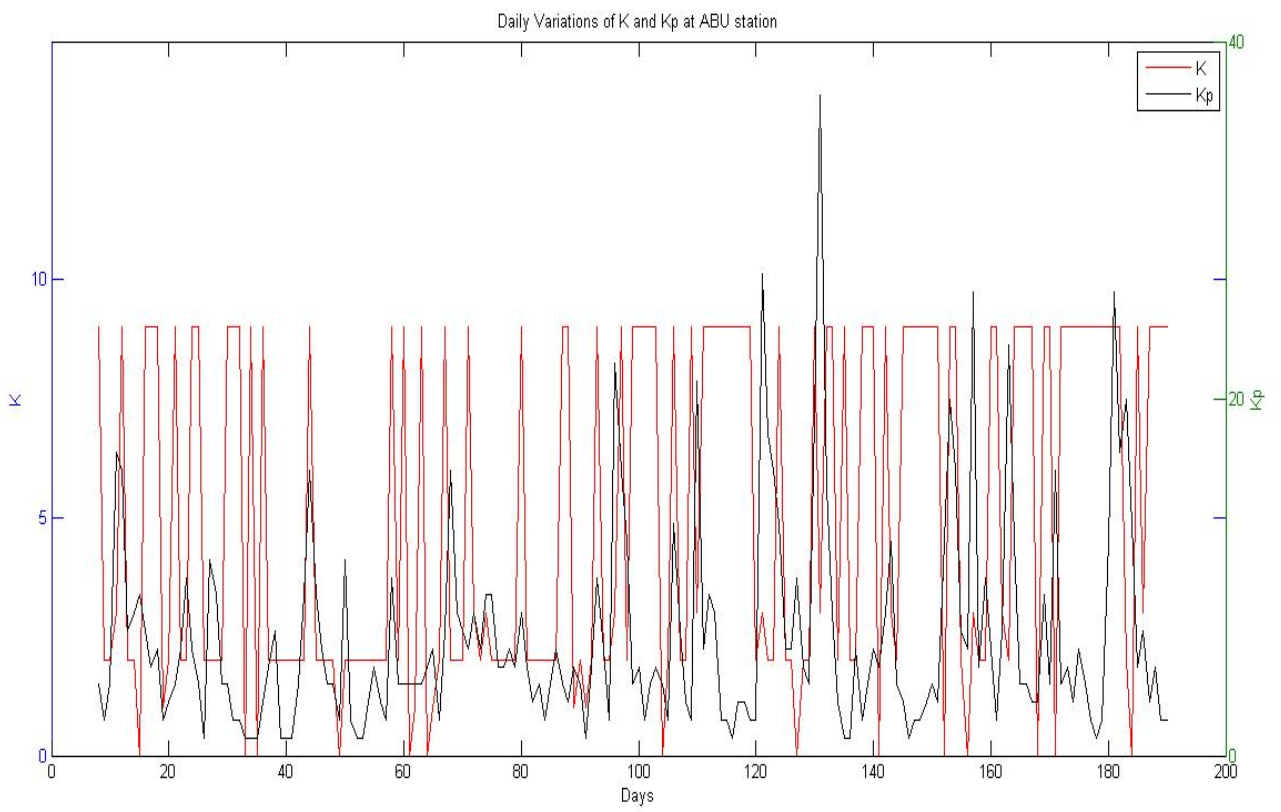

Figure 4: Daily variations of $A$ and $A p$ at $A B U$ Stations.

(C) 2013 The Authors. Journal Compilation C 2013 European Center of Sustainable Development. 
The measure of the strength of the linear relationship between the variables ( $\mathrm{K}$, $\mathrm{A}$ and Ap, Kp) are as follows; ABU (0.9882 and 0.9495), LAG (0.9920 and $0.9510)$ and ILR (0.9877 and 0.9121) respectively. This indicates an almost perfect positive linear relationship between $\mathrm{K}$ and $\mathrm{A}$ indices obtained from the three stations, this implies that as $\mathrm{K}$ increases in its values, $\mathrm{A}$ also increases in its values via an exact linear rule. The measure of the degree of how much the variability of a factor can be caused or explained by its relationship to another factor between the variables $(\mathrm{K}, \mathrm{A}$ and $\mathrm{Ap}, \mathrm{Kp})$ for ABU, LAG and ILR stations (97.65\% and $90.16 \%, 98.41 \%$ and $90.44 \%, 97.56 \%$ and $83.19 \%$ ) indicates a better goodness of fit. Locally generated $(K, A)$ indices showed a better correlation coefficient and coefficient of determination $\left(\mathrm{R}^{2}\right)$ than the standard $(\mathrm{Kp}, \mathrm{Ap})$ indices. As shown in table 3, 4 and 5; the two way sample t-test between the variables $\{(\mathrm{K}, \mathrm{Kp}),(\mathrm{A}, \mathrm{Ap}),(\mathrm{K}, \mathrm{Ap}),(\mathrm{A}, \mathrm{Kp})\}$ for the three stations $(h=1)$ indicates a rejection of the null hypothesis at the $5 \%$ significance level, this implies that the respective variables are dependent upon each other thus there is a significant linear relationship between the mean values of the variables. The probability of observing the values as extreme or more extreme of the test statistic as indicated by the $\mathrm{p}$ values for the respective stations is less than 0.05 , which implies that, the $95 \%$ confidence interval on the mean of the difference does not contain 0 . Standard $\mathrm{Kp}$ varies higher than locally generated $\mathrm{K}$ index while locally generated A varies higher than standardized $\mathrm{K}$ index for the respective stations.

Prior to the space age, Electromagnetic waves below the VHF-range (VHF = very high frequencies; $30-300 \mathrm{MHz}$ ) reflected and attenuated in the ionospheric D-, E-, and F- layers depending on the frequency, time of the day, geographic location, and solar activity could be observed on the ground (4). The geomagnetic activity, likewise observed on the ground, was attributed to upper atmospheric electric currents, known today as currents flowing within the ionospheric dynamo region and the magnetosphere (22).

When electromagnetic radiation from the Sun strips an electron off a neutral constituent in our atmosphere, the resulting electron can spiral along a magnetic field line. Thus the condition of the ionosphere depends on the state of Earth's magnetic field. This is important because Earth's magnetic field plays a big part in the propagation of radio signals around our planet. Generally an A index at or below 15, or a $\mathrm{K}$ index at or below 3, is best for propagation.

$\mathrm{K}$ indices reflect the geomagnetic conditions (solar particle effects on the earth's magnetic field). Lower $\mathrm{K}$ values connotes quieter ionosphere. Trends in the $\mathrm{K}$ indexes are important to watch, When $\mathrm{K}$ rises, $\mathrm{HF}$ propagation conditions worsen, particularly towards the Polar Regions. On VHF bands, a high $\mathrm{K}$ index would mean the possibility of an Aurora opening (23). According to (24), K variations are all irregular disturbances of the geomagnetic field caused by solar 
particle radiation within the 3-h interval concerned. All other regular and irregular disturbances are non $\mathrm{K}$ variations. Geomagnetic activity is thus the occurrence of $\mathrm{K}$ variations. 'A' Values below 10 are very desirable for HF communications. Higher A numbers can mean excessive absorption of HF radio waves due to increased storm conditions in the ionosphere. The larger the $\mathrm{A}$ index, the more active the Earth's magnetic field becomes due to a storm from the sun. The smaller the index, the quieter it is. Sometimes changes in the suns activity can cause big changes in Kp. At other times, large $\mathrm{Kp}$ values can indicate sudden rearrangements of the Earth's magnetic field due to the solar wind.

The locally generated averaged $\mathrm{K}$ yearly mean over each station showed that the relative level of activity in the ionosphere over Lagos (4.60), Ilorin (4.13), and Abuja (3.5) station indicated a minor storm for Lagos, an active ionosphere over Ilorin and a transition phase from unsettled to active ionosphere for Abuja. With respect to its corresponding locally generated A Index, The ionosphere over Abuja (27) is said to be active, while that of Lagos (97.28) and Ilorin (58.03) stations shows transition from major to severe and minor to major Ionospheric / geomagnetic storm respectively. Thus adequate measures need to be put in place to mitigate or risk its effect on critical infrastructures relying on Space and Land based assets etc.

\section{Conclusion}

We have demonstrated that with a simple algorithm and appropriate computer code, $\mathrm{K}$ and $\mathrm{A}$ indices from ground based magnetometers was generated and used to characterize the ionosphere. The ionosphere over the three stations is relatively active (4.08), thus setting the baseline for geomagnetic indices in Nigeria. By virtue of the study, we can now provide valuable inputs to local and global models for the prediction of Ionospheric behaviour and can also provide real time assessment of the (local and global) geomagnetic activity over Nigeria thus mitigate geomagnetic and Ionospheric storms.

\section{References}

Ian Poole. The Ionosphere and Radio wave Propagation. Accessed 28 March 2012. Available: http://www.radioelectronics.com/info/propagation/ionospheric/ionosphere.php

Chalmers, J.A, 1962. "The first suggestion of the ionosphere” J. atmos. Terr-Phys, Pp. 26, 219-221. Joshua, T. W., 2007. "Assessment of the impact of various ionospheric models on high-frequency signal ray tracing". Thesis presented to the faculty Department of Engineering Physics, Graduate School of Engineering and Management, Air Force Institute of Technology, Air University, Air Education and Training Command, Ohio, USA.

Rawer, K., 1993. "Wave Propagation in the Ionosphere". Kluwer Acad. Publ., Dordrecht. ISBN 0-7923-0775-5. 
Stan S., Koen, S., Rene W., 2010. "Local Operational Geomagnetic Index K Calculation (KLOGIC) from digital ground-based magnetic measurements".

Parkinson, W.D., 1983. "Introduction to geomagnetism" Edinburgh: Scottish Academic Press, Pp. 114-118.

Mayaud, P.N., 1980. "Derivation, Meaning, and Use of Geomagnetic Indices" Geophysical Monograph 22. Washington, DC: American Geophysical Union.

Rangarajan, G.K., 1989. "Indices of geomagnetic activity” In Jacobs, J.A. (ed.), Geomagnetism, Vol. 2. London, UK: Academic Press, Pp. 323-384.

McPherron, R.L., 1995. "Standard indices of geomagnetic activity" In Kivelson, M.G., and Russell, C.T. (eds.), Introduction to Space Physics. Cambridge, UK: Cambridge University Press, Pp. 451-458.

Shea, M.A., and Smart, D.F., 1998. "Space Weather: The Effects on Operations in Space" Advance Space Research, 22, Pp. 29-38.

Bartels, J., Heck, N.H., and Johnston, H.F., 1939. "The three-hour range index measuring magnetic activity, Terrestrial Magnetism and Atmospheric Electricity" Pp. 44, 411-454.

Davies, K., 1990. “Ionospheric Radio” Peter Peregrinus Ltd. London.

Loredana P. and Giorgiana De Franceschi 1998. "Solar, Ionospheric and geomagnetic indices" Annali Di Geofisica, Vol. 41, Pp. 5-6.

Menvielle, M., and Berthelier, A., 1991. "The K Derived Planetary Indices: Description and Availability" Reviews of Geophysics, 29, Pp. 415-432.

Bartels, J., 1951. “Int. Union Geod. Geophys” IATME Bull., no. 12e, Pp. 109.

Yumoto, K., and the MAGDAS Group, 2006. "ILWS Workshop" Hotel Cidade de Goa, Goa, India, February 19-24.

Yumoto, K., and the MAGDAS Group, 2006b. "In Solar Influence on the Heliosphere and Earth's Environment: Recent Progress and Prospects" edited by Gopalswamy, N., and Bhattacharya, A., ISBN-81-87099-40-2, Pp. 399

Yumoto, K., and the MAGDAS group, 2007. Bull. Astr. Soc. India. 35, Pp. 511.

Uozumi, T., Yumoto, K., Kitamura, K., Abe, S., Kakinami, Y., Shinohara, M., Yoshikawa, A., Kawano, H., Ueno, T., Tokunaga, T., Obrou, O., Rabiu, A.B., Adimula, I.A., Othman, M., Fairos, R.E.S., Otadoy and MAGDAS Group, 2008. "Earth, Planets and Space" 60, Pp. 785.

Maeda, K., 1937. "Measurement of the G-region of the Ionosphere" Electrotech. Journal, Japan, Pp. 1, 66-67.

Rabiu, A.B., Adimula, I.A., Yumoto, K., Adeniyi, J.O., Maeda, G., 2009. "Earth, Moon, and Planets" DOI: 10.1007/s11038- 008-9290-7, Pp. 104, 173.

Chapman, S., Bartels, J., 1951. "Geomagnetism", Clarendon Press, New York.

Anonymous. Description of propagation indexes: Accessed 26 April 2012.

Available: http://www.dxmaps.com/propindex.html

Siebert, M., 1971. “Geomagnetic activity indices”, In: Dieminger, W., Hartmann, G.K., Leitinger, R., (Ed.), the Upper Atmosphere - Data Analysis and Interpretation, Springer, Berlin, pp. 887- 911. 